\title{
RESPON VARIETAS KEDELAI (Glycine max L. Merr) PADA TINGKAT KELENGASAN TANAH YANG BERBEDA
}

\section{(Soy Variety Response (Glycine Max L. Merr) at a Different Level of Human Kelingan)}

\author{
Aminah $^{1}$, Nirwana ${ }^{1}$, Marlyana S. Palad ${ }^{2}$ \\ ${ }^{1)}$ Fakultas Pertanian Universitas Muslim Indonesia \\ 2.) Fakultas Pertanian Universitas Cokroaminoto
}

\begin{abstract}
The growth ofsoybean in wet land and dry land not always supported by optimal soil moisture conditions to high level production. In the wet field saturated soil often found in the lower area until remain water irrigation cannot wasted to lower area. Once effort of soybean cultivation in the saturated soil used variety which tolerance in saturated soil.The experiment was conducted in a glasshouse at BALITSEREAL Maros, from May 2013 until Sep 2013. A completely randomized design $4 x 4$ factorial arrangement with three replication was used. The first factor is level soil moisture content, field capacity, 5\% above field capacity, $15 \%$ above field capacity, 25\% above field capacity, and the second factor is soybean varieties Wilis, Sinabung, Kaba and Dieng.Result showed there is no interactionbetweensoil moisture content and varieties to number of pods and seed weight. Interaction caused treatment occurred to number of leaf, leaf area, total dry matter, dry weight nodules, crop growth rate, net assimilation rate, spesific leaf area, and leaf area ratio. Treatment of soil moisture content which 5\% and 15\% above field capacity showed higher productivity than soil moisture content $25 \%$ above field capacity. Varieties Sinabung and Kaba showed higher productivity than varieties Wilis and Dien.
\end{abstract}

Keywords : Soybean, Soil Moisture, Growth and production.

\section{PENDAHULUAN}

\section{Latar Belakang}

Budidaya tanaman kedelai akhirakhir ini semakin berkembang pesat sesuai dengan perkembangan teknologi dalam bidang pertanian, tetapi selama dasawarsa terakhir telah dirasakan adanya kondisi iklim yang tidak menentu, khususnya saat, jumlah dan distribusi curah hujan yang turun pada awal musim kemarau cukup berlebihan di lahan sawah sehingga di beberapa daerah terjadi kondisi tanah jenuh air. Tanaman kedelai yang mengalami cekaman jenuh air ini banyak terjadi di daerah Jateng, Jatim, Bali dan NTB dan diperkirakan mencapai areal seluas 500.000 ha, kesempatan untuk meningkatkan hasil kedelai dengan sistem jenuh air menjadi terbuka lebar, disarankan untuk bertanam kedelai jenuh air pada musim kemarau dengan intensitas sinar matahari yang tinggi sehingga hasil optimal dapat dicapai (Sumarno, 1986). 

Adisarwanto (2000) berpendapat bahwa, genangan air sebenarnya merupakan fenomena yang sering terjadi di lahan sawah, kelembaban tanah yang berlebihan merupakan kendala dalam upaya meningkatkan produksi kedelai di lahan sawah. Tanpa saluran drainase yang baik, kelembaban tanah menjadi tinggi dan menyebabkan pertumbuhan tanaman kedelai menjadi tidak optimal, lingkungan tanah jenuh air yang ekstrem akan mengakibatkan akar tanaman menjadi busuk karena kekurangan oksigen sehingga penyerapan unsur hara terhambat dan akhirnya tanaman tumbuh kerdil (Yuanita, dkk. 2014) Ada 2 (dua) istilah yang dikenal sehubungan dengan masalah kelebihan air, yaitu tanah tergenang (water logging) dan tanah jenuh air (saturated soil). Kondisi air yang menggenang tersebut disebabkan oleh beberapa faktor yaitu : (1). bertambah lamanya periode musim hujan, (2) kuantitas curah hujan yang cukup deras setelah tanam kedelai, (3) sistem draenase yang belum optimal.

Pengaruh negatif kondisi tanah jenuh air tersebut dapat dikurangi, salah satu upaya adalah dengan membuat saluran draenase dan tinggi permukaan air di dalam saluran draenase agar selalu tetap pada tingkatan tertentu. Hal ini terkait dengan kapasitastanaman kedelai untuk memperbaiki pertumbuhannya melalui proses aklimatisasi.

Salah satu upaya di dalam budidaya kedelai dalam kondisi jenuh air adalah dengan memanfaatkan varitas yang toleran terhadap kondisi jenuh air. Pengelolaan air berupa penerapan drainase dimaksudkan memperbaiki kondisi fisik tanah utamanya aerasi sehingga dapat meningkatkan efisiensi pemupukan, pada kondisi tanah jenuh air penerapan saluran drainase tidak mungkin dilakukan, pemanfaatan genotipa toleran jenuh air merupakan pemecahan yang mudah dilakukan. Tujuan penelitian Untuk mendapatkan varietas kedelai yang toleran terhadap tingkat penjenuhan air pada periode kritis tertentu dan mendapatkan tingkat kondisi air tanah yang dapat ditolerir oleh tanaman agar produksinya tidak menurun.

Penelitian dilaksanakan di rumah kaca Universitas Hasanudin Makasar, dimulai pada bulan Mei sampai September 2013. Tanah yang digunakan adalah jenis 
tanah Entisol (Aluvial) yang diperoleh dari Balitjas Maros. Bahan percobaan meliputi : kedelai varietas Wilis, Sinabung, Kaba dan Dieng. Pupuk anorganik Urea, SP-36 dan $\mathrm{KCl} 50-50-50$.

Percobaan dilaksanakan di rumah kaca dengan menggunakan rancangan lingkungan Rancangan Acak Kelompok yang disusun secara faktorial dan diulang 3 kali. Macam perlakuan dari masingmasing faktor adalah

Faktor I : Tingkat kelengasan tanah pada fase vegetatif terdiri dari 4 taraf $: \mathrm{J0}=\mathrm{Ka}-$ pasitas LapangJ1 = Tingkat kelengasan tanah $5 \%$ diatas kapasitas lapang $\quad \mathrm{J} 2=$ Tingkat kelengasan tanah $15 \%$ diatas kapasitas lapang J3 = Tingkat kelengasan tanah $25 \%$ diatas kapasitas lapang

Faktor II : Varietas kedelai

$\mathrm{V} 1=$ Wilis $\quad \mathrm{V} 2=$ Sinabung $\mathrm{V} 3=$ Kaba $\mathrm{V} 4=$ Dieng

Sebelum dimasukkan di polybag tanah dikeringkan dan dihaluskan.Setelah itu tanah yang sudah dihaluskan dimasukkan ke dalam polybag dengan berat $6 \mathrm{~kg}$ per polybag. Polybag diletakkan pada tempat sesuai dengan perlakuan dan rancangan lingkungan, untuk perlakuan tanpa penjenuhan polybag diletakkan di tempat kosong, sedangkan untuk perlakuan penjenuhan, polybag diletakkan pada kotak penjenuhan Pengairan dilakukan untuk mendapatkan tingkat jenuh air yang berbeda maka tingkat jenuh air di sekitar polybag dibedakan sesuai perlakuan.Tinggi air tersebut dipertahankan selama perlakuan yaitu antara 15 30 hari setelah tanam. Pengairan dilakukan dengan cara mengecek masing-masing polybag sesuai dengan perlakuan, yaitu pada kondisi tingkat kelengasan tanah 5\% diatas kapasitas lapang diperlakukan jarak ketinggian air $15 \mathrm{~cm}$, tingkat kelengasan tanah $15 \%$ diperlakukan jarak ketinggian air $10 \mathrm{~cm}$ dan tingkat kelengasan tanah $25 \%$ diatas kapasitas lapang diperlakukan jarak ketinggian air $5 \mathrm{~cm}$. Pengairan dipertahankan pada sebelum dan sesudah perlakuan pada kondisi kapasitas lapang .

Pengamatan dilakukan pada umur 30, 45, 60 hst (hari setelah tanam), dengan pengambilan 2 tanaman contoh. Peubah pertumbuhan yang diamati adalah :

Tinggi tanaman, Jumlah daun per tanaman, Luas daun per tanaman, Kadar klorofil daun, Berat bintil akar per tanaman, Berat 
kering total per tanaman, Umur saat mulai berbunga,

Pengamatan hasil dan komponen hasil diamati pada saat panen, dengan mengambil 4 tanaman contoh. Komponen hasil yang diamati meliputi :
Berat biji per tanaman :Jumlah polong isi dan polong hampa, Berat 100 biji, Indeks Panen, Umur panen

\section{HASIL DAN PEMBAHASAN}

Tabel 1. Interaksi Antara Kelengasan Tanah dengan Varietas pada Berat Kering Tanaman

\begin{tabular}{|l|c|c|c|}
\hline \multirow{2}{*}{\multicolumn{1}{|c|}{ Perlakuan }} & \multicolumn{3}{|c|}{ Berat Kering Tanaman (g) } \\
\cline { 2 - 4 } & $\mathbf{3 0}$ hst & $\mathbf{4 5}$ hst & $\mathbf{6 0}$ hst \\
\hline Kapasitas Lapang x Wilis & $2,10 \mathrm{~b}$ & $9,89 \mathrm{bcde}$ & $20,54 \mathrm{cde}$ \\
5\% diatas KL x Wilis & $1,44 \mathrm{ef}$ & $10,24 \mathrm{abc}$ & $20,35 \mathrm{cde}$ \\
15\% diatas KL x Wilis & $2,01 \mathrm{~b}$ & $10,65 \mathrm{ab}$ & $22,38 \mathrm{abc}$ \\
25\% diatas KL x Wilis & $1,40 \mathrm{ef}$ & $9,18 \mathrm{def}$ & $20,47 \mathrm{cde}$ \\
Kapasitas Lapang x Sinabung & $2,42 \mathrm{a}$ & $8,97 \mathrm{f}$ & $23,68 \mathrm{ab}$ \\
$\mathbf{5 \%}$ diatas KL x Sinabung & $1,77 \mathrm{c}$ & $10,83 \mathrm{a}$ & $21,17 \mathrm{cde}$ \\
15\% diatas KL x Sinabung & $2,18 \mathrm{~b}$ & $10,81 \mathrm{a}$ & $24,19 \mathrm{a}$ \\
25\% diatas KL x Sinabung & $1,36 \mathrm{ef}$ & $9,41 \mathrm{cdef}$ & $20,38 \mathrm{cde}$ \\
Kapasitas Lapang x Kaba & $2,49 \mathrm{a}$ & $9,53 \mathrm{cdef}$ & $21,91 \mathrm{bcd}$ \\
5\% diatas KL x Kaba & $1,68 \mathrm{~cd}$ & $9,39 \mathrm{cdef}$ & $21,09 \mathrm{cde}$ \\
15\% diatas KL x Kaba & $2,07 \mathrm{~b}$ & $10,75 \mathrm{ab}$ & $23,70 \mathrm{ab}$ \\
25\% diatas KL x Kaba & $1,55 \mathrm{de}$ & $9,07 \mathrm{ef}$ & $20,78 \mathrm{cde}$ \\
Kapasitas Lapang x Dieng & $1,32 \mathrm{f}$ & $8,71 \mathrm{fg}$ & $17,81 \mathrm{f}$ \\
$\mathbf{5 \%}$ diatas KL x Dieng & $1,29 \mathrm{f}$ & $8,97 \mathrm{f}$ & $19,94 \mathrm{de}$ \\
15\% diatas KL x Dieng & $1,32 \mathrm{f}$ & $9,15 \mathrm{ef}$ & $19,68 \mathrm{ef}$ \\
\hline
\end{tabular}




\begin{tabular}{|l|c|c|c|}
\hline \multirow{2}{*}{ Perlakuan } & \multicolumn{3}{|c|}{ Berat Kering Tanaman (g) } \\
\cline { 2 - 4 } & $\mathbf{3 0}$ hst & $\mathbf{4 5}$ hst & $\mathbf{6 0}$ hst \\
\hline 25\% diatas KL x Dieng & $1,26 \mathrm{f}$ & $7,83 \mathrm{~g}$ & $19,82 \mathrm{de}$ \\
\hline KK (\%) & 11,62 & 7,23 & 5,24 \\
\hline
\end{tabular}

Keterangan : Angka-angka pada kolom yang sama yang didampingi dengan huruf yang sama tidak berbeda nyata berdasarkan Uji Jarak Duncan pada taraf 5

Tabel 2. Interaksi Antara Kelengasan Tanah dengan Varietas pada Berat Kering Bintil Effektif

\begin{tabular}{|l|c|c|c|}
\hline \multirow{2}{*}{ Perlakuan } & \multicolumn{3}{c|}{ Berat Kering Bintil Effektif (10 $\left.\mathbf{- 2}^{-2} \mathbf{~}\right)$} \\
\cline { 2 - 4 } & $\mathbf{3 0}$ hst & $\mathbf{4 5}$ hst & $\mathbf{6 0}$ hst \\
\hline Kapasitas Lapang x Wilis & $16,66 \mathrm{a}$ & $56,98 \mathrm{def}$ & $80,26 \mathrm{bcd}$ \\
5\% diatas KL x Wilis & $13,29 \mathrm{~b}$ & $54,02 \mathrm{efg}$ & $72,43 \mathrm{def}$ \\
15\% diatas KL x Wilis & $16,59 \mathrm{a}$ & $66,91 \mathrm{c}$ & $83,63 \mathrm{bc}$ \\
25\% diatas KL x Wilis & $12,94 \mathrm{~b}$ & 56,39 & $62,06 \mathrm{f}$ \\
Kapasitas Lapang x Sinabung & $15,44 \mathrm{ab}$ & $58,21 \mathrm{def}$ & $85,98 \mathrm{~b}$ \\
5\% diatas KL x Sinabung & $10,01 \mathrm{c}$ & 55,99 & $65,87 \mathrm{def}$ \\
15\% diatas KL x Sinabung & $15,18 \mathrm{ab}$ & $91,31 \mathrm{~b}$ & $98,10 \mathrm{a}$ \\
25\% diatas KL x Sinabung & $9,46 \mathrm{c}$ & $67,43 \mathrm{c}$ & $75,82 \mathrm{bcd}$ \\
Kapasitas Lapang x Kaba & $14,51 \mathrm{ab}$ & $61,57 \mathrm{cde}$ & $84,55 \mathrm{bc}$ \\
5\% diatas KL x Kaba & $13,69 \mathrm{~b}$ & $60,60 \mathrm{cde}$ & $64,37 \mathrm{ef}$ \\
15\% diatas KL x Kaba & $14,39 \mathrm{ab}$ & $98,72 \mathrm{a}$ & $85,44 \mathrm{~b}$ \\
\hline
\end{tabular}


Aminah : Respon Varietas Kedelai (Glycine max L. Merr) pada Tingkat Kelegasan Tanah berbeda

\begin{tabular}{|l|c|c|c|}
\hline \multirow{2}{*}{\multicolumn{1}{|c|}{ Perlakuan }} & \multicolumn{3}{|c|}{ Berat Kering Bintil Effektif $\left(\mathbf{1 0}^{-2} \mathbf{~ m g}\right)$} \\
\cline { 2 - 4 } & $\mathbf{3 0}$ hst & $\mathbf{4 5}$ hst & $\mathbf{6 0}$ hst \\
\hline $25 \%$ diatas KL x Kaba & $9,38 \mathrm{c}$ & $58,03 \mathrm{def}$ & $72,16 \mathrm{def}$ \\
Kapasitas Lapang x Dieng & $8,18 \mathrm{~cd}$ & $54,35 \mathrm{efg}$ & $75,75 \mathrm{bcd}$ \\
$5 \%$ diatas KL x Dieng & $7,62 \mathrm{~cd}$ & $52,34 \mathrm{fg}$ & $62,93 \mathrm{f}$ \\
$15 \%$ diatas KL x Dieng & $8.59 \mathrm{~cd}$ & $62,63 \mathrm{~cd}$ & $74,65 \mathrm{cde}$ \\
$25 \%$ diatas KL x Dieng & $6,15 \mathrm{~d}$ & $48,43 \mathrm{~g}$ & $64,59 \mathrm{ef}$ \\
\hline KK $(\%)$ & 11,18 & 7,07 & 7,46 \\
\hline
\end{tabular}

Tabel 3. Pengaruh Kelengasan Tanah dan Varietas pada Berbagai Parameter

\begin{tabular}{|l|c|c|c|c|}
\hline \multicolumn{1}{|c|}{ Perlakuan } & $\begin{array}{c}\text { Kadar Air } \\
\text { Tanah (\%) }\end{array}$ & $\begin{array}{c}\text { Jumlah } \\
\text { Polong }\end{array}$ & $\begin{array}{c}\text { Berat 100 } \\
\text { biji(g) }\end{array}$ & $\begin{array}{c}\text { Indeks } \\
\text { Panen }\end{array}$ \\
\hline Kelengasan tanah & & & & \\
Kapasitas Lapang & $31,37 \mathrm{~d}$ & $65,44 \mathrm{~b}$ & 10,54 & 0,50 \\
5\% diatas kapasitas lapang & $33.07 \mathrm{c}$ & $72,96 \mathrm{a}$ & 10,33 & 0,53 \\
15\% diatas kapasitas lapang & $37,18 \mathrm{~b}$ & $71,48 \mathrm{a}$ & 10,42 & 0,50 \\
25\% diatas kapasitas lapang & $41,87 \mathrm{a}$ & $62,40 \mathrm{~b}$ & 10,64 & 0,49 \\
\hline BNT 5\% & 2.84 & 1,79 & tn & tn \\
\hline Varietas & & & & \\
Wilis & 36,54 & $55,85 \mathrm{c}$ & $10,85 \mathrm{~b}$ & $0,51 \mathrm{a}$ \\
Sinabung & 35,76 & $60,98 \mathrm{~b}$ & $11,76 \mathrm{a}$ & $0,53 \mathrm{a}$ \\
Kaba & 36,57 & $62,48 \mathrm{~b}$ & $11,38 \mathrm{ab}$ & $0,51 \mathrm{a}$ \\
Dieng & 36,59 & $92,96 \mathrm{a}$ & $7,91 \mathrm{c}$ & $0,48 \mathrm{~b}$ \\
\hline BNT 5\% & tn & 1,79 & 0,55 & 0,03 \\
\hline KK (\%) & 1,97 & 9,10 & 8,25 & 7,54 \\
\hline
\end{tabular}

Keterangan : Angka-angka pada kolom yang sama yang didampingi dengan huruf yang sama tidak berbeda nyata berdasarkan BNT pada taraf $5 \%$. 
Hasil pengamatan pada peubah kadar air tanah menunjukkan bahwa tingkat lengas tanah 5\% menunjukkan kadar air tanah 5,14\% diatas kapasitas lapang, tingkat lengas tanah $15 \%$ menunjukkan kadar air tanah $15.62 \%$ di atas kapasitas lapang, sedangkan penjenuhan tingkat lengas tanah $25 \%$ menunjukkan kadar air tanah $25,07 \%$ di atas kapasitas lapang.

Pertumbuhan tanaman pada fase vegetatif dipengaruhi oleh kelengasan tanah $15 \%$, dimana pada kondisi ini tanaman mampu bertoleransi dan mengadakan perbaikan pertumbuhan kembali, ditunjukkan oleh adanya peningkatan, berat kering akar, berat bintil effektif, berat kering total tanaman yang semuanya ini akan berpengaruh pula pada produktivitas tanaman, pertumbuhan tanaman merupakan manifestasi banyak proses mulai dari penyediaan karbohidrat oleh organ fotosintesis. Bintil akar merupakan salah satu komponen penting dalam pertumbuhan tanaman. kedelai, karena kemampuan biologis mengikat unsur hara $\mathrm{N}$ udara. Untuk itu perkembangan bintil akar menjadi faktor penting tanaman kedelai pada kondisi jenuh air.
Pengamatan peubah berat kering bintil effektif menunjukkan bahwa varietas Kaba dan Sinabung memiliki bintil effektif yang lebih berat dibandingkan dengan varietas Wilis, dan Dieng. untuk pengamatan berat kering total tanaman varietas Sinabung dan Kaba menunjukkan berat kering total lebih tinggi dibanding varietas Wilis dan Dieng, hal ini disebabkan varietas Sinabung dan Kaba mempunyai kemampuan adaptasi dan aklimatisasi yang lebih cepat dibandingkan dengan varietas lainnya sehingga mampu menghasilkan biomassa tanaman yang lebih tinggi, tetapi untuk perkembangan selanjutnya varietas Wilis dan Dieng juga mampu mengadakan aklimatisasi yang sama dengan varietas Sinabung dan Kaba.

Hasil penelitian terhadap komponen hasil produksi tanaman meliputi pengamatan umur panen, jumlah polong, jumlah polong hampa, berat kering biji, berat 100 biji dan indeks panen. Komponen hasil merupakan hasil proses pertumbuhan yang mengolah masukan substrat menjadi produk pertumbuhan.

Berdasarkan hasil penelitian terhadap peubah jumlah polong dan jumlah 
polong hampa tidak terdapat interaksi antara perlakuan penjenuhan dengan varietas. Sedangkan penelitian Adisarwanto, Purwaningrahayu dan Riwanodja (2000) diperoleh interaksi antara varietas dan kondisi tanah jenuh air terhadap jumlah polong isi. Jumlah polong pada tingkat lengas tanah $5 \%$ dan $15 \%$ menunjukkan jumlah polong yang lebih tinggi dibanding dengan kondisi kapasitas lapang dan tingkat lengas tanah 25\% diatas kapasitas lapang. Varietas Dieng menunjukkan jumlah polong terbesar dibandingkan dengan varietas Wilis, Sinbung dan Kaba, tetapi meskipun varietas Dieng memiliki jumlah polong yang banyak tetapi ukuran bijinya kecil-kecil sehingga berpengaruh pada berat bijinya.Pengamatan terhadap peubah berat kering biji menunjukkan tidak terjadinya interaksi antara perlakuan kelengasan tanah dengan varietas. Adisarwanto dan Suhartina (2000) melaporkan bahwa di tanah Entisol diperoleh interaksi antara kondisi tanah jenuh air dan varietas pada berat biji. Interaksi antara kondisi tanah jenuh air dan varietas kedelai terhadap variabel berat biji pada berbagai fase pertumbuhan di tanah Entisol Genteng, dengan masing-masing perlakuan adalah varietas Dieng, Wils, Kawi, Bromo, Argomulyo dengan kondisi jenuh air pada 0-15 hst, 15-30 hst, 30-45 hst. Hal ini diduga karena pada penelitian ini dilakukan di lapang sehingga banyak faktor lingkungan yang berpengaruh pada berat biji.Perlakuan kelengasan tanah menunjukkan bahwa tingkat lengas tanah $15 \%$ menunjukkan hasil yang besar dan berbeda dibandingkan dengan perlakuan tingkat lengas tanah $25 \%$ diatas kapasitas lapang, hal ini disebabkan tanaman mampu beradaptasi dan mempunyai daya aklimatisasi pada kondisi tingkat lengas tanah15\%. Perbedaan varietas menunjukkan bahwa varietas Sinabung dan Kaba memberikan berat kering biji yang lebih besar dibandingkan dengan varietas Wilis dan Dieng, hal ini dikarenakan varietas Sinabung dan Kaba mempunyai daya adaptasi yang tinggi pada kondisi penjenuhan, ditunjukkan dengan adanya peningkatan pola pertumbuhan vegetatif meliputi peningkatan jumlah daun, luas daun, berat kering akar, berat bintil effektif, berat kering tanaman, laju pertumbuhan relatif tanaman, laju asimilasi bersih, luas 
daun spesifik, nisbah luas daun, sehingga menghasilkan produksi tanaman berupa biji yang cukup besar pula. Hasil penelitian Pasaribu, dkk (2006) menunjukkan perbedaan respon varietas kedelai terhadap cara tanam basah (jenuh air) dan cara kering.Ada 3 (tiga) varietas yaitu Wilis, B3043 dan B 7207-1 menunjukkan sangat adaptif pada kondisi jenuh air dengan memberikan kenaikan sekitar $18 \%$ dibanding cara tanam kering.

Pengamatan terhadap peubah berat 100 biji, perlakuan penjenuhan tidak menunjukkan adanya pengaruh, sedangkan perbedaan varietas menunjukkan bahwa berat 100 biji yang besar didapatkan pada varietas Sinabung dan Kaba. Hal ini menunjukkan bahwa varietas Sinabung dan Kaba memiliki ukuran biji yang lebih besar dibandingkan dengan varietas Wilis dan Dieng. Ukuran biji berhubungan dengan daya toleransi varietas terhadap kondisi budidaya basah atau penjenuhan, bahwa kedelai berukuran biji besar lebih toleran terhadap penjenuhan dibandingkan dengan kedelai berukuran biji sedang (varie-tas Wilis) dan kedelai berukuran biji kecil (varietas Dieng). Ghulahmahdi, M (2010) menyatakan bahwa kedelai berbiji besar (Amerikana) lebih toleran dibanding dengan kedelai berbiji kecil .

\section{KESIMPULAN}

1. Terdapat interaksi antara varietas kedelai dengan penjenuhan air pada pengamatan, berat bintil effektif, berat kering tanaman

2. Varietas Sinabung dan Kaba memiliki produktivitas yang lebih tinggi dibandingkan dengan varietas Wilis dan Dieng.

3. Perlakuan kelengasan tanah $15 \%$ diatas kapasitas lapang meingkatkan pertumbuhan dan hasil yang lebih tinggi daripada kelengasan tanah yang lain

\section{DAFTAR PUSTAKA}

Adi, M.M. Soegito, Rodiah dan Hadi Purnomo. 1990. Tanggapan beberapa Genotipe Kedelai terhadap Cara Budidaya Basah dan Kering. Risalah Seminar Hasil Penelitian Tanaman Pangan Tahun 1990. Balittan Malang Hal 8-13

Adisarwanto, T. 2001. Bertanam Kedelai di Tanah Jenuh Air (Opsi Innovative Pengelolaan Air untuk Kedelai di Lahan Sawah Irrigasi).Buletin Palawija.Jurnal Tinjauan Ilmiah Penelitian 
Tanaman Palawija. 1 (2) : 2001. 16 hal

Adisarwanto, T. dan Suhartina. 2000. Toleransi Kedelai terhadap Kondisi Tanah Jenuh Air pada Berbagai Fase Pertumbuhan. Laporan Teknis Tahun 1999/2000. 10 hal

Adisarwanto, T. , R.D. Purwaningrahayu dan Riwanodja. 2000. Respon Kedelai terhadap Pemupukan pada Kondisi Tanah Jenuh Air. Laporan Teknis Balitkabi 2000. 7 hal

Ghulamahdi, M., F, Rumawas, J, Wiroadmojo dan J, Koswara. 2010. Pengaruh Pemupukan Fosfor dan Varietas terhadap Pertumbuhan dan Produksi Tanaman Kedelai pada Budidaya Jenuh Air. Forum Pasca Sarjana. IPB Bogor : 14 (1-2) : 25-34

Madi, I (1997). Pengaruh Penggenangan TerhadapHasil dan Pertumbuhan Tiga Varietas Kedelai (Glycine max (L) Merr). Tesis Fakultas Pasca- sarjana. Institut Pertanian Bogor. Bogor. 74 hal 